\title{
Treatment of Purified Terephthalic Acid Wastewater by Ozone Catalytic Oxidation Method
}

\author{
$\mathrm{Xi} \mathrm{Lu}{ }^{1}$, Shuqian Xie ${ }^{2}$, Shuai $\mathrm{Li}^{2}{ }^{2}$, Jun Zhou ${ }^{2}$, Wenquan Sun ${ }^{2, *}$, Yanhua $\mathrm{Xu}^{1}$ and Yongjun Sun ${ }^{2, *}$ (I) \\ 1 School of Environmental Sciences and Engineering, Nanjing Tech University, Nanjing 211816, China; \\ strong_119@126.com (X.L.); xuyh@njtech.edu.cn (Y.X.) \\ 2 College of Urban Construction, Nanjing Tech University, Nanjing 211800, China; xsq980310@163.com (S.X.); \\ LS19850052669@163.com (S.L.); zhoujun0913@126.com (J.Z.) \\ * Correspondence: coneflower@163.com (W.S.); sunyongjun@njtech.edu.cn (Y.S.)
}

Citation: Lu, X.; Xie, S.; Li, S.; Zhou, J.; Sun, W.; Xu, Y.; Sun, Y. Treatment of Purified Terephthalic Acid Wastewater by Ozone Catalytic Oxidation Method. Water 2021, 13, 1906. https://doi.org/10.3390/ w13141906

Academic Editor: José Alberto Herrera-Melián

Received: 2 June 2021

Accepted: 27 June 2021

Published: 9 July 2021

Publisher's Note: MDPI stays neutral with regard to jurisdictional claims in published maps and institutional affiliations.

Copyright: (C) 2021 by the authors. Licensee MDPI, Basel, Switzerland. This article is an open access article distributed under the terms and conditions of the Creative Commons Attribution (CC BY) license (https:/ / creativecommons.org/licenses/by/ $4.0 /)$.

\begin{abstract}
In this study, a Cu-Ce@Az ozone catalyst with multiple active components was prepared through the impregnation method to treat purified terephthalic acid (PTA) wastewater, and characterized by $\mathrm{X}$-ray diffraction, $\mathrm{X}$-ray fluorescence spectroscopy, scanning electron microscopy, specific surface area analysis, $\mathrm{X}$-ray energy spectroscopy, $\mathrm{X}$-ray photoelectron spectroscopy, and other methods. The $\mathrm{Cu}-\mathrm{Ce} @ \mathrm{Az}$ ozone catalyst had a developed pore structure with a large specific surface area and crystal structure. After calcination, the metallic elements $\mathrm{Cu}$ and $\mathrm{Ce}$ existed in the state of oxides $\mathrm{CuO}$ and $\mathrm{CeO}_{2}$. The effects of reaction time, solution $\mathrm{pH}$, catalyst dosage, and ozone dosage on the catalytic oxidation performance of the $\mathrm{Cu}-\mathrm{Ce} @ \mathrm{Az}$ ozone catalyst were studied. Adding tert-butanol reduced the removal rate of COD from the PTA wastewater through the catalytic oxidation system, which proves that a $\mathrm{Cu}-\mathrm{Ce} @ \mathrm{Az}$ ozone catalyst treatment process of PTA wastewater follows the free-radical reaction mechanism. The results of 3D fluorescence spectroscopy analysis show that the organic matter in the PTA wastewater was converted into tryptophan organic matter and aromatic organic matter after the reaction of the catalytic oxidation system. Ultraviolet absorption spectroscopy analysis indicated that in unsaturated chemical bonds, some conjugated structures and benzene ring structures of organic matter in the PTA wastewater were destroyed.
\end{abstract}

Keywords: ozone catalyst; catalytic oxidation; PTA wastewater; impregnation method; artificial zeolite

\section{Introduction}

Purified terephthalic acid (PTA) is mainly used to synthesize polyethylene terephthalate (PET), which in turn is used to make carbonic acid, soft drink bottles, water bottles, flip caps, plastics, and other products [1]. PTA wastewater mainly comes from the recovery of tower-bottom drainage in the oxidation process of xylene and the mother liquor recovery stage in the hydrorefining reaction process [2]. The composition of pollutants in PTA wastewater is complex and its properties fluctuate greatly, although the pollutants are mainly aromatic compounds. PTA wastewater has a higher organic load, which leads to an increased toxicity and chemical oxygen demand (COD). If the wastewater is directly discharged, it causes great harm to aquatic environments. Therefore, PTA wastewater must be treated [3].

At present, the commonly used treatment methods include biochemical, physical, and chemical treatment. The biochemical treatment methods include biological-aerobic, biological-anaerobic, and anaerobic-aerobic secondary biological treatment [4]. The biochemical treatment method for PTA wastewater has disadvantages, such as an inconvenient experimental operation, large resource consumption, long reaction-cycle span, strict environmental requirements, and susceptibility to interference from other substances. The physical and chemical treatment methods include adsorption, flocculation, and advanced oxidation processes [5]. General physical and chemical treatment methods have a higher cost and lower treatment efficiency than others, but are often used to treat organic 
wastewater with poor biodegradability. The advanced oxidation process that uses free radical reactions to degrade compounds has proven effective in the degradation of highconcentration organic wastewater [6]. Among them, the electrochemical oxidation method is widely used. In this process, the pollutants can be oxidized by the electron transfer reaction between the organic matter and the electrode surface or the action of hydroxyl radicals [7]. Anodizing is a relatively common electrochemical advanced oxidation method, which has certain prospects for the treatment of non-biodegradable pollutants. The nature of the anode has an important influence on the oxidability of the anodizing method. In the process of treating wastewater, the anode material is required not only to have a high oxygen evolution overpotential, but also to have high stability and corrosion resistance when treating wastewater. Early electrode materials such as graphite, activated carbon, and other conventional materials had a high overpotential for oxygen evolution, but these electrodes were easily corroded and easily passivated [8]. Therefore, various electrode materials, such as thin-film oxide anodes, noble metals, and carbon-based anodes have been studied [9]. However, these electrodes have some defects in the electrochemical oxidation of pollutants. The efficiency of anodization also depends on some key operating conditions, such as the initial concentration of organic pollutants, current density, and the presence or absence of metal cations. On the other hand, anodization is expensive and consumes a lot of energy, which has become an important factor in the large-scale application of this technology [10]. In advanced oxidation processes, ozone catalytic oxidation technology has attracted attention due to its high efficiency and absence of secondary pollution [11]. This process can efficiently treat organic pollutants in PTA wastewater. In the presence of a catalyst, ozone molecules can generate hydroxyl radicals $(\bullet \mathrm{OH})$, and organic compounds can be quickly and indiscriminately mineralized into small molecular substances without introducing other pollutants. Therefore, this process has a certain application value in treating PTA wastewater [12].

In the ozone catalytic oxidation system, selecting active components for catalytic ozonation is important. A cerium (Ce)-based metal oxidation catalyst has good redox performance and high oxygen storage capacity, which can increase the hydroxyl yield. However, applying Ce in wastewater treatment can cause a significant loss of Ce ions, which may cause serious secondary pollution [13]. Manganese can decompose ozone by generating active oxidants, making it one of the most active species that degrade organic compounds in the presence of ozone. The catalytic activity of the supported metal typically depends on the characteristics of the support material, such as surface area, pore volume, and morphology [14]. As a porous aluminosilicate with a framework structure, a zeolite has the advantages of a large specific surface area, developed pores, good reusability, and good stability, and can selectively adsorb organic molecules in wastewater [15]. At the same time, a zeolite can provide a huge surface for the dispersion of $\mathrm{Ce}$, which can stabilize the Ce in the catalyst and prevent it from leaching into the solution [16]. Therefore, to reduce the leaching of metal ions and obtain a low-cost active oxygen treatment process, an artificial zeolite loaded with $\mathrm{Ce}$ and $\mathrm{Cu}$ could be synthesized as a heterogeneous catalyst for ozone oxidation [17].

In this study, an artificial zeolite loaded with $\mathrm{Ce}$ and $\mathrm{Cu}$ was prepared through the impregnation roasting method as a high-efficiency heterogeneous catalyst, $\mathrm{Cu}-\mathrm{Ce} @ \mathrm{Az}$, for catalytic ozonation, and used to treat PTA wastewater. X-ray diffraction, $\mathrm{X}$-ray fluorescence spectroscopy, scanning electron microscopy, specific surface area analysis (BET), X-ray energy spectroscopy, X-ray photoelectron spectroscopy, and other technologies were applied to analyze the structure of the supported $\mathrm{Cu}-\mathrm{Ce} @ \mathrm{Az}$ ozone catalyst. To comprehensively investigate the performance of the catalytic ozonation system, the effects of reaction time, catalyst dosage, $\mathrm{pH}$, ozone dosage, and other factors on the catalytic oxidation performance of the $\mathrm{Cu}-\mathrm{Ce} @ \mathrm{Az}$ catalyst were studied. Finally, the catalytic oxidation mechanism of the $\mathrm{Cu}-\mathrm{Ce} @ \mathrm{Az}$ catalyst was examined. 


\section{Materials and Methods}

\subsection{Materials}

Copper nitrate, cerium nitrate, and potassium bromate (all of analytical grade) were purchased from Sinopharm Chemical Reagent Co. Ltd. (Shanghai, China). Potassium bromide, sodium thiosulfate, starch, potassium iodide, potassium dichromate, silver sulfate, mercury sulfate, ethanol, and tert-butanol (all analytically pure) were purchased from Nanjing Chemical Reagent Co. Ltd. (Nanjing, China). The artificial zeolite is of high-quality grade. All reagents are analytically pure and used directly without further purification. The PTA wastewater used in the experiment mainly comes from the biochemical effluent of the secondary sedimentation tank of a sewage treatment station of a petrochemical enterprise in Jiangsu (the main product is PTA). The water-quality test results of the biochemical effluent are presented in Table 1.

Table 1. Water quality of PTA wastewater obtained from a petrochemical company.

\begin{tabular}{ccc}
\hline Test Index & Unit & Detection Value \\
\hline $\mathrm{COD}$ & $\mathrm{mg} / \mathrm{L}$ & 178.6 \\
$\mathrm{NH}_{4}^{+}-\mathrm{N}$ & $\mathrm{mg} / \mathrm{L}$ & 0.24 \\
$\mathrm{pH}$ & $/$ & 8.50 \\
Turbidity & $\mathrm{NTU}$ & 7.63 \\
Conductivity & $\mathrm{HS} / \mathrm{cm}$ & 11.76 \\
Total phosphorus & $\mathrm{mg} / \mathrm{L}$ & 0.93 \\
Total nitrogen & $\mathrm{mg} / \mathrm{L}$ & 0.65 \\
TOC & $\mathrm{mg} / \mathrm{L}$ & 59.94 \\
\hline
\end{tabular}

\subsection{Catalyst Preparation and Characterization}

First, the cleaned artificial zeolite was added to $0.1 \mathrm{~mol} / \mathrm{L}$ of hydrochloric acid solution and soaked for $24 \mathrm{~h}$. After soaking in hydrochloric acid, the material was rinsed with pure water repeatedly until the eluate was neutral. Subsequently, pure water was added, and the mixture was boiled on an electric stove for $30 \mathrm{~min}$. After repeated rinsing, the catalyst was placed in an oven to dry for later use. A certain mass of $\mathrm{Cu}\left(\mathrm{NO}_{3}\right)_{2} \cdot 6 \mathrm{H}_{2} \mathrm{O}$ and $\mathrm{Ce}\left(\mathrm{NO}_{3}\right)_{3} \cdot 6 \mathrm{H}_{2} \mathrm{O}$ was weighed, and a certain concentration of metal element precursor solution was configured and placed in a conical flask. A certain amount of pretreated artificial zeolite was transferred into an Erlenmeyer flask and placed in a water-bath shaker for $12 \mathrm{~h}$, and the temperature of the water bath was set to $35^{\circ} \mathrm{C}$. The impregnated carrier was taken out, the excess impregnating liquid was filtered out, and the catalyst was placed in an oven to dry for $12 \mathrm{~h}$. The dried catalyst was transferred into a crucible and placed in a muffle furnace, baked at a certain temperature for a certain period, and then taken out and packaged for use after cooling.

The surface micromorphology of the $\mathrm{Cu}-\mathrm{Ce} @ \mathrm{Az}$ ozone catalyst was characterized by scanning electron microscope (Crossbeam 340/550, Zeiss, Germany). X-ray diffraction (D8 Advance, Bruker, Germany) was used to characterize the crystal structure of the transition metals in the Cu-Ce@Az ozone catalyst. BET (ASAP2460, Micromeritics, United States) was used to characterize the pore volume, pore size, and adsorption performance of the catalyst. X-ray fluorescence spectrometry (Axios Pw4400, Panaco, The Netherlands) was used to characterize the content of metal elements and metal oxides in the $\mathrm{Cu}-\mathrm{Ce} @ \mathrm{Az}$ ozone catalyst. The distribution of each element in the catalyst was measured by X-ray energy spectroscopy (Kratos AXIS Ultra DLD, Shimadzu Corporation, Kyoto, Japan).

\subsection{Ozone Catalytic Oxidation Experiment}

As shown in Figure 1, the catalytic reaction device included an ozone generator (CF-G-3-10g, Qingdao Guolin, Qingdao, China), a wastewater treatment device, and an exhaust gas absorption treatment device. At the beginning of the experiment, the oxygen cylinder provided high-purity oxygen in the ozone generator for pre-blowing for $15 \mathrm{~min}$. After the pre-blowing, a quantitative catalyst was placed in the reactor and a quantitative 
amount of wastewater was injected. The ozone generator was switched on again to adjust the inlet pressure and ozone flow. The oxygen generated ozone through high-voltage discharge inside the ozone generator, and the ozone fully contacted the catalyst through the sand-core aeration head and the microporous aeration plate to conduct the catalytic oxidation reaction. The ozone output could be controlled by adjusting the gas flowmeter of the ozone generator, and the incompletely reacted ozone tail gas was discharged outdoors after passing through the two-stage tail-gas absorption treatment device. A water outlet was reserved on the side wall of the reactor, and samples were obtained regularly during the catalytic oxidation reaction to determine COD. COD in the wastewater was determined by the potassium dichromate method. The exhaust gas generated in the experiment was discharged after treatment using an exhaust gas absorption device (20\% KI solution).

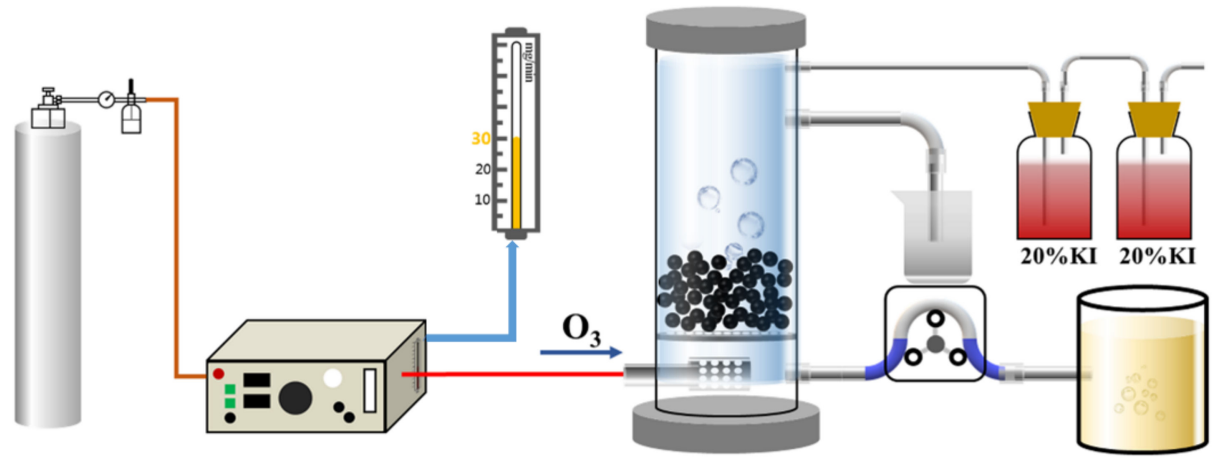

Figure 1. Ozone catalytic reaction flowchart.

\section{Results and Discussion}

\subsection{Preparation of $\mathrm{Cu}-\mathrm{Ce} @ A z$ Catalyst}

Figure S1 shows that the $\mathrm{Cu}-\mathrm{Ce} @ \mathrm{Az}$ ozone catalyst had a higher adsorption rate of pollutants in wastewater within $60 \mathrm{~min}$. When the adsorption time exceeded $120 \mathrm{~min}$, the removal rate of COD stabilized at 5.3\%. As shown in Figure S2, when the ratio of the metal element $\mathrm{Cu}$ was increased, the effect of the $\mathrm{Cu}-\mathrm{Ce} @ \mathrm{Az}$ ozone catalyst on the treatment of PTA biochemical tailwater worsened. When the impregnation ratio of $\mathrm{Cu}$ to Ce was 1:3 in the $\mathrm{Cu}-\mathrm{Ce} @ \mathrm{Az}$ ozone, the catalyst had the best treatment effect on the PTA biochemical tailwater. Under the optimum condition of the element impregnation ratio, the COD removal rate of the PTA biochemical tailwater was $72.4 \%$. Figure S3 shows that the optimal calcination temperature of the $\mathrm{Cu}-\mathrm{Ce} @ \mathrm{Az}$ ozone catalyst was also $400{ }^{\circ} \mathrm{C}$. The $\mathrm{Cu}-\mathrm{Ce} @ \mathrm{Az}$ ozone catalyst prepared under the optimal calcination temperature condition treated PTA biochemical tailwater for $70 \mathrm{~min}$, and the removal rate of COD in wastewater was $77.5 \%$. As shown in Figure S4, when the calcination time was 2.5-3.5 h, the catalytic performance of the $\mathrm{Cu}-\mathrm{Ce} @ \mathrm{Az}$ ozone catalyst increased with the increase of the calcination time. When the calcination time exceeded $3.5 \mathrm{~h}$, the catalytic performance of the catalyst gradually decreased. From the perspective of the COD removal rate of the PTA biochemical tailwater, when the roasting time was $3.5 \mathrm{~h}$, the reaction was $70 \mathrm{~min}$ and the COD removal rate reached $79.5 \%$.

\subsection{Physical and Chemical Properties of Cu-Ce@Az Ozone Catalyst}

As presented in Figure 2, the Cu-Ce@Az ozone catalyst had many crystal particles on the surface at $400{ }^{\circ} \mathrm{C}$, and the catalytic activity of the catalyst was improved compared with those at $300^{\circ} \mathrm{C}$ and $350^{\circ} \mathrm{C}$. At $450{ }^{\circ} \mathrm{C}$ and $500{ }^{\circ} \mathrm{C}$, the crystal particles grew too large to wrap on the surface of the catalyst, which blocked the pore structure of the catalyst and reduced its catalytic activity. After repeated use, the pore structure of the catalyst was filled with substances in the PTA wastewater, causing serious blockage of the pore structure. As shown in Figure S5, the samples had obvious characteristic peaks at $2 \theta=27.4^{\circ}$, $33.1^{\circ}$ and $37.1^{\circ}$, which coincide with $\mathrm{Fe}_{2} \mathrm{O}_{3}$ (JCPDS Card No.89-0596), $\mathrm{SiO}_{2}$ (JCPDS Card No.71-0650), and $\mathrm{Al}_{2} \mathrm{O}_{3}$ (JCPDS Card No.13-0373), respectively, indicating that the artificial 
zeolite contained $\mathrm{Fe}, \mathrm{Si}, \mathrm{Al}$, and other metal elements. Compared with the blank sample, the catalyst sample had obvious characteristic peaks of $\mathrm{CeO}_{2}$ (JCPDS Card No.34-0394) at $2 \theta=29^{\circ}, 33^{\circ}, 48^{\circ}$, and $57^{\circ}$, corresponding to the (111), (200), (220), and (311) planes, respectively [18]. The two characteristic peaks at $2 \theta=36^{\circ}$ and $39^{\circ}$ correspond to the (111) and (200) planes of the $\mathrm{CuO}$ crystal [19]. Under conditions of 300,350 , and $400{ }^{\circ} \mathrm{C}$, with the temperature increase, the intensity of the diffraction peaks of $\mathrm{CeO}_{2}$ at $2 \theta=29^{\circ}, 33^{\circ}, 48^{\circ}$, and $57^{\circ}$ continued to increase, and the intensity of the diffraction peaks of $\mathrm{CuO}$ (JCPDS Card No.48-1548) at $2 \theta=36^{\circ}$ and $39^{\circ}$ also continued to rise. This phenomenon shows that in this temperature range, the increase in temperature is conducive to the formation of $\mathrm{CuO}$ and $\mathrm{CeO}_{2}$ crystal forms. As the temperature increased to $450{ }^{\circ} \mathrm{C}$ and $500{ }^{\circ} \mathrm{C}$, the diffraction peaks of $\mathrm{CeO}_{2}$ at $2 \theta=29^{\circ}, 33^{\circ}, 48^{\circ}$, and $57^{\circ}$ and the diffraction peaks of $\mathrm{CuO}$ at $2 \theta=36^{\circ}$ and $39^{\circ}$ showed a decrease in intensity, which shows that the $\mathrm{CuO}$ and $\mathrm{CeO}_{2}$ crystal forms gradually disappeared with the increase of the calcination temperature. The reason for this may be that the temperature was too high to destroy the structure of the $\mathrm{Cu}-\mathrm{Ce} @ \mathrm{Az}$ ozone catalyst, thereby affecting the formation of $\mathrm{CuO}$ and $\mathrm{CeO}_{2}$ crystal forms [20]. In addition, repeated use reduced the crystal forms of $\mathrm{CuO}$ and $\mathrm{CeO}_{2}$, which may have been due to the loss of metal components caused by repeated use, thereby affecting the diffraction peaks of $\mathrm{CuO}$ and $\mathrm{CeO}_{2}$ [21].

Table S1 shows that the specific surface area of the $\mathrm{Cu}-\mathrm{Ce} @ \mathrm{Az}$ ozone catalyst was larger than that of the blank artificial zeolite, which indicates that the supported metal elements $\mathrm{Cu}$ and $\mathrm{Ce}$ were converted into the corresponding metal oxides $\mathrm{CuO}$ and $\mathrm{CeO}_{2}$. The pore volume of the $\mathrm{Cu}-\mathrm{Ce} @ \mathrm{Az}$ ozone catalyst was also improved, but the pore diameter was slightly reduced. At the same time, the results show that after repeated use the BET specific surface area, pore volume, and pore diameter of the $\mathrm{Cu}-\mathrm{Ce} @ \mathrm{Az}$ ozone catalyst decreased [22]. As presented in Figure S6 and Table S2, compared with the blank carrier, the metallic elements $\mathrm{Cu}$ and $\mathrm{Ce}$ were successfully loaded inside and on the surface of the carrier, and then converted into $\mathrm{CuO}$ and $\mathrm{CeO} 2$ after calcination. The content of $\mathrm{CuO}$ and $\mathrm{CeO}_{2}$ was $1.8941 \%$ and $6.6818 \%$, respectively. After the $\mathrm{Cu}-\mathrm{Ce} @ \mathrm{Az}$ ozone catalyst was reused 30 times, the content of $\mathrm{CuO}$ and $\mathrm{CeO}_{2}$ accounted for $1.7673 \%$ and $6.5275 \%$, respectively. As shown in Table S3, the main components of the artificial zeolite blank carrier were $\mathrm{Al}_{2} \mathrm{O}_{3}$ and $\mathrm{SiO}_{2}$, and $\mathrm{Cu}$ and $\mathrm{Ce}$ were found in the $\mathrm{Cu}-\mathrm{Ce} @ \mathrm{Az}$ ozone catalyst. The weight percentages were $2.52 \%$ and $2.68 \%$, respectively. The existence of $\mathrm{Cu}$ and $\mathrm{Ce}$ indicates that the $\mathrm{Cu}-\mathrm{Ce} @ \mathrm{Az}$ ozone catalyst was successfully prepared using the impregnation method. After 30 uses, the weight percentages of $\mathrm{Cu}$ and $\mathrm{Ce}$ in the Cu-Ce@Az ozone catalyst were $2.39 \%$ and $2.33 \%$, respectively. Compared with the unused $\mathrm{Cu}-\mathrm{Ce} @ \mathrm{Az}$ ozone catalyst, the content of the supported metal elements $\mathrm{Cu}$ and $\mathrm{Ce}$ were slightly reduced. As shown in Figure S7, in the blank carrier $\mathrm{Al}, \mathrm{Si}, \mathrm{Na}, \mathrm{Mg}$, and other metal elements existed in the form of $\mathrm{Al}_{2} \mathrm{O}_{3}, \mathrm{SiO}_{2}, \mathrm{Na}_{2} \mathrm{O}$, and $\mathrm{MgO}$. The electron binding energies of $\mathrm{Cu} 2 \mathrm{p}$ and $\mathrm{Ce} 3 \mathrm{~d}$ are $883.7 \mathrm{eV}$ and $897.97 \mathrm{eV}$, respectively, which indicate that the atomic valence of $\mathrm{Cu}$ was +2 and the valence of $\mathrm{Ce}$ was +4 in the $\mathrm{Cu}-\mathrm{Ce} @ \mathrm{Az}$ ozone catalyst. Repeated use caused the loss of the loaded metal and affected the size of the peaks of the $\mathrm{Cu} 2 \mathrm{p}$ and Ce3d energy spectra [23].

\subsection{Degradation of PTA Wastewater by Cu-Ce@Az Ozone Catalyst \\ 3.3.1. Effect of Reaction Time on Catalytic Performance}

As shown in Figure 3, the COD content in the PTA wastewater gradually decreased as the catalytic reaction time increased. When the reaction time was 10-50 min, the COD removal rate in the PTA wastewater was the fastest; when the reaction time was $50 \mathrm{~min}$, the COD removal rate in the PTA wastewater reached $74.28 \%$. The removal rate of COD in the PTA wastewater increased slowly during the reaction time of 50-70 min. Thereafter, the reaction time continued to increase to $100 \mathrm{~min}$, but the removal rate of COD and TOC in PTA wastewater did not increase significantly. That is, the effluent water quality was not significantly improved. Although the treatment effect was good at a reaction time of 
$100 \mathrm{~min}$, in practical applications a longer reaction time indicates a high-cost operation. Therefore, the catalytic reaction time in this experiment was $70 \mathrm{~min}$.

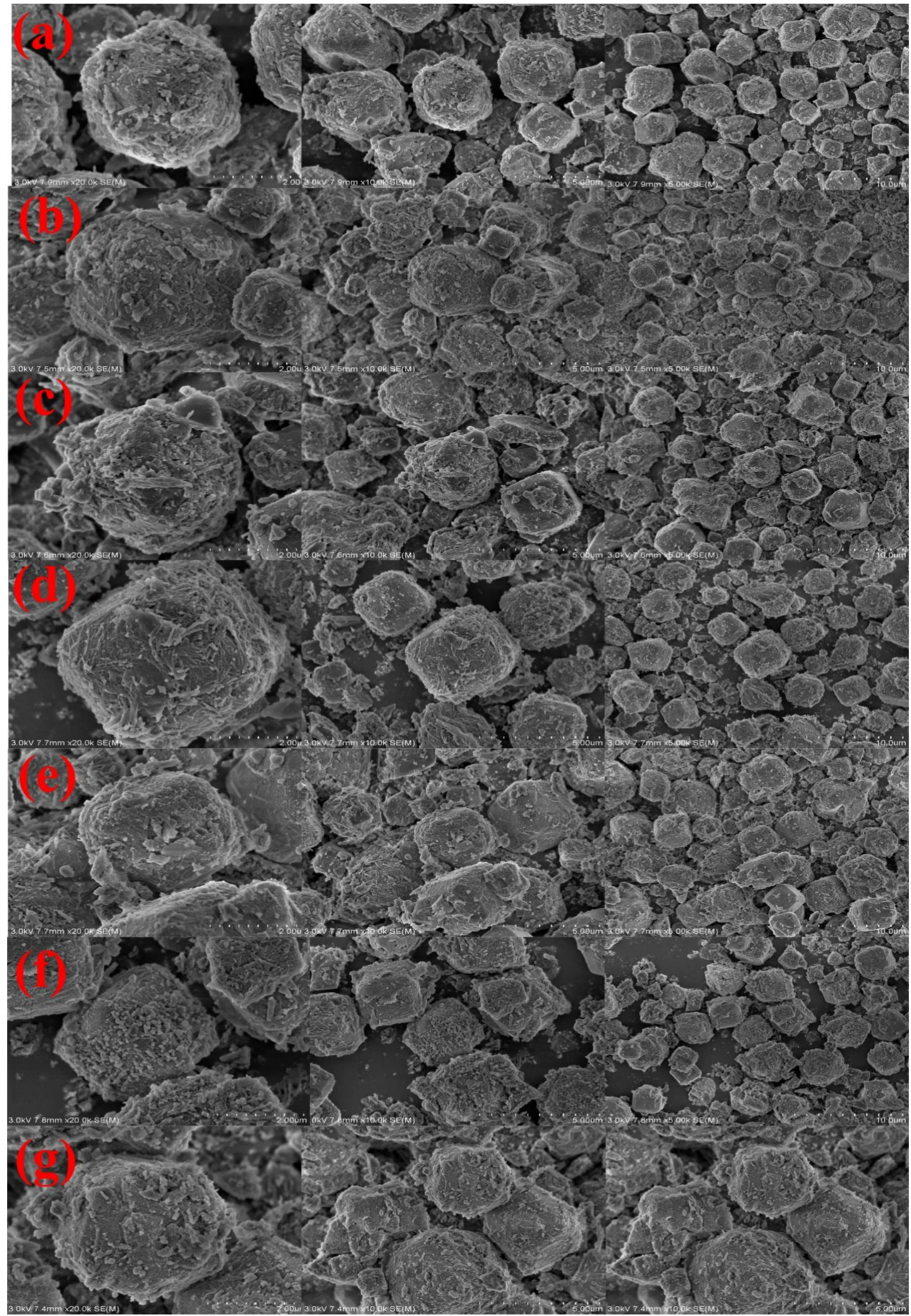

Figure 2. SEM characterization: (a) synthetic zeolite, (b) $300{ }^{\circ} \mathrm{C}$, (c) $350{ }^{\circ} \mathrm{C}$, (d) $400{ }^{\circ} \mathrm{C}$, (e) $450{ }^{\circ} \mathrm{C}$, (f) $500{ }^{\circ} \mathrm{C}$, and (g) $\mathrm{Cu}-\mathrm{Ce} @ \mathrm{Az}$ after utilization 30 times. 


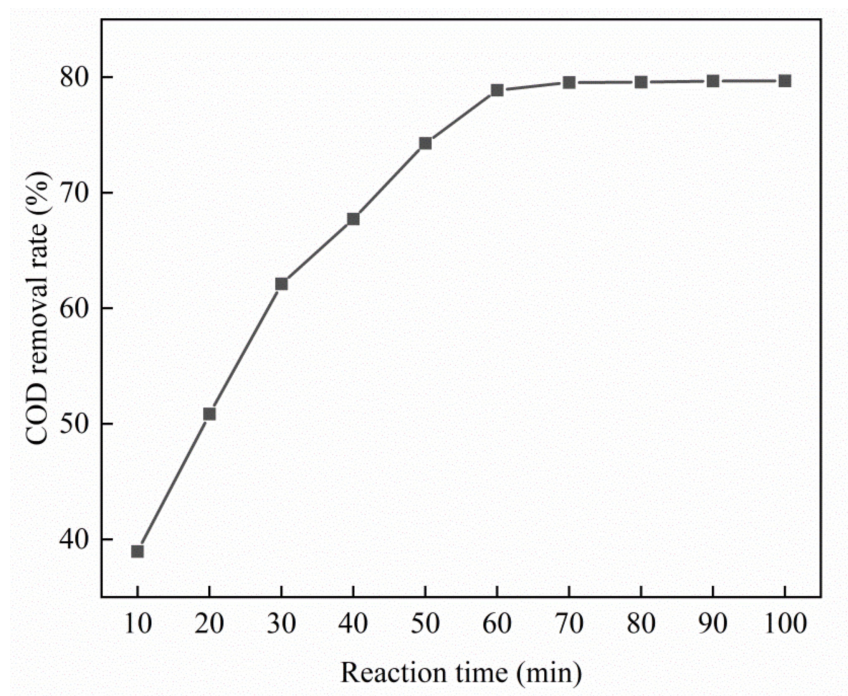

Figure 3. Effect of reaction time on catalytic performance of $\mathrm{Cu}-\mathrm{Ce} @ \mathrm{Az}$ catalysts.

\subsubsection{Effect of $\mathrm{pH}$ on Catalytic Performance}

Figure 4 shows that as the $\mathrm{pH}$ of PTA wastewater increased, the COD removal rate of wastewater also increased. Experiments indicated that under alkaline conditions, the removal rate of COD and total phenols of PTA wastewater was higher than under acidic conditions. When $\mathrm{pH}=11$, the removal rate of the COD of experimental wastewater reached the maximum value of $80.1 \%$. Under alkaline conditions, the $\mathrm{Cu}-\mathrm{Ce} @ \mathrm{Az}$ ozone catalyst could better degrade the PTA wastewater. By adjusting the $\mathrm{pH}$ to different levels, we found that, although increasing the $\mathrm{pH}$ helped improve the removal rate of wastewater $\mathrm{COD}$, the increase of the removal rate in the interval of $\mathrm{pH}=3-7$ is greater than that in the interval of $\mathrm{pH}=7-11$. When $\mathrm{pH}=9$, the COD removal rate of PTA wastewater by the $\mathrm{Cu}-\mathrm{Ce} @ \mathrm{Az}$ ozone catalyst was $79.4 \%$ and continued to increase to $\mathrm{pH}=11$. The COD removal rate of PTA wastewater was only increased by $0.7 \%$. The degradation effect of the ozone catalytic oxidation system could be improved under alkaline conditions, probably due to the existence of more $\mathrm{OH}$ - under alkaline conditions, which can combine with ozone to produce more hydroxyl radicals [24], thereby improving the degradation effect. On the other hand, it is also possible that alkaline conditions destroy the structure of the organic matter in the wastewater, causing it to dissociate so that it can be oxidized better and faster [25].

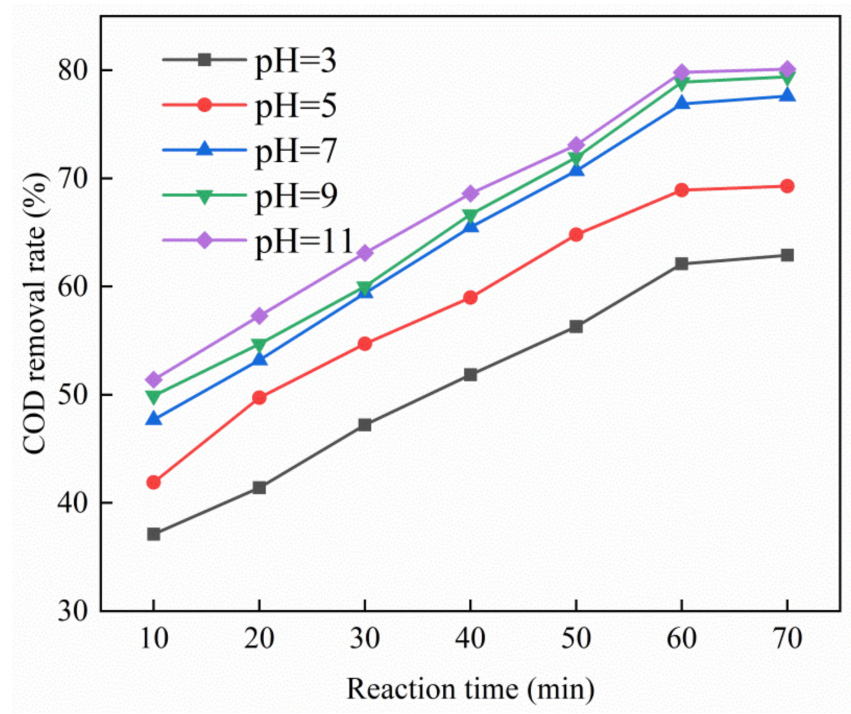

Figure 4. Effect of $\mathrm{pH}$ on catalytic performance of $\mathrm{Cu}-\mathrm{Ce} @ \mathrm{Az}$ catalysts. 


\subsubsection{Effect of Ozone Dosage on Catalytic Performance}

Figure 5 shows that the greater the amount of ozone added, the higher the removal rate of COD from the PTA wastewater by the $\mathrm{Cu}-\mathrm{Ce} @ \mathrm{Az}$ ozone catalyst. When the amount of ozone added reached the maximum value of $2.5 \mathrm{~g} / \mathrm{h}$, the removal rate of COD reached $83.9 \%$. When the ozone dosage was $0.5-2.0 \mathrm{~g} / \mathrm{h}$, the $\mathrm{Cu}-\mathrm{Ce} @ \mathrm{Az}$ ozone catalyst had a significant increase in the degradation efficiency of the PTA wastewater. At 2.0-2.5 g/h, the COD removal rate of the PTA wastewater increased slowly. This condition may be due to the increase in the dosage and interaction of ozone causing the $\mathrm{Cu}-\mathrm{Ce} @ \mathrm{Az}$ ozone catalyst to produce more hydroxyl radicals [26]. When it reaches a certain level, the ozone concentration in a reaction system reaches a saturated state. At this time, increasing the amount of ozone generated cannot significantly improve the efficiency of wastewater degradation [27]. In this experiment, the optimal ozone generation amount was $2.0 \mathrm{~g} / \mathrm{h}$, and the removal rate of COD in the PTA wastewater under this condition was $82.4 \%$.

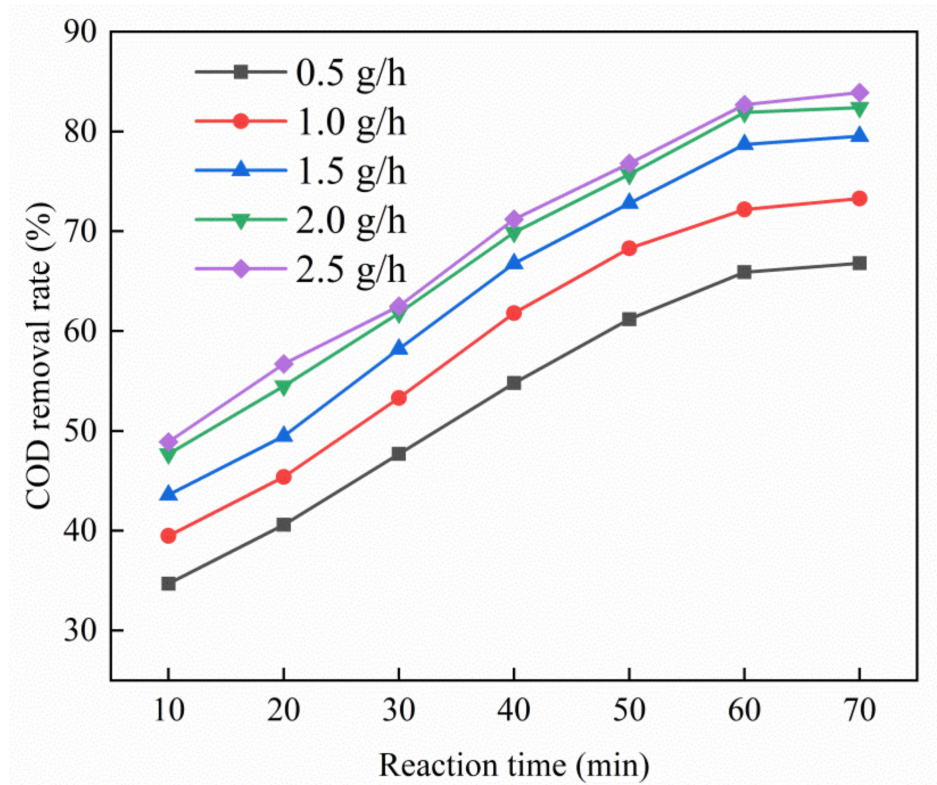

Figure 5. Effect of ozone dosage on catalytic performance of $\mathrm{Cu}-\mathrm{Ce} @ \mathrm{Az}$ catalysts.

\subsubsection{Effect of Catalyst Dosage on Catalytic Performance}

As shown in Figure 6, increasing the dosage of the $\mathrm{Cu}-\mathrm{Ce} @ \mathrm{Az}$ ozone catalyst increased the removal rate of COD. When the catalyst dosage was $15-30 \mathrm{~g} / 350 \mathrm{~mL}$, the removal rate of COD of PTA wastewater by the $\mathrm{Cu}-\mathrm{Ce} @ \mathrm{Az}$ ozone catalyst also increased, eventually reaching $84.2 \%$. When the dosage of the catalyst was increased to $35 \mathrm{~g} / 350 \mathrm{~mL}$, the $\mathrm{Cu}-\mathrm{Ce} @ \mathrm{Az}$ ozone catalyst had a slower increase in the COD removal rate of the PTA wastewater. However, compared with the previous stage, the COD removal rate was only increased by $0.1 \%$. The reason why the $\mathrm{Cu}-\mathrm{Ce} @ \mathrm{Az}$ ozone catalyst could combine with ozone to treat the PTA wastewater is the existence of active sites in the $\mathrm{Cu}-\mathrm{Ce} @ \mathrm{Az}$ ozone catalyst that could combine with ozone. The increase in the dosage of $\mathrm{Cu}-\mathrm{Ce} @ \mathrm{Az}$ ozone catalyst provided more active sites for combination with ozone [28]. At the same time, the more active the sites, the faster the ozone decomposition, and the more hydroxyl radicals are produced, thereby improving the oxidation efficiency of the PTA wastewater. When the concentration of ozone in the wastewater was constant, we continued to increase the dosage of the $\mathrm{Cu}-\mathrm{Ce} @ \mathrm{Az}$ ozone catalyst. As the ozone and internal active sites of the catalyst reached saturation, the newly added active sites could not be effectively used [29], and increasing the dosage of large $\mathrm{Cu}-\mathrm{Ce} @ \mathrm{Az}$ ozone catalyst affected the contact area of the active group and wastewater [30]. Thus, $30 \mathrm{~g} / 350 \mathrm{~mL}$ was selected as the best dosage. 


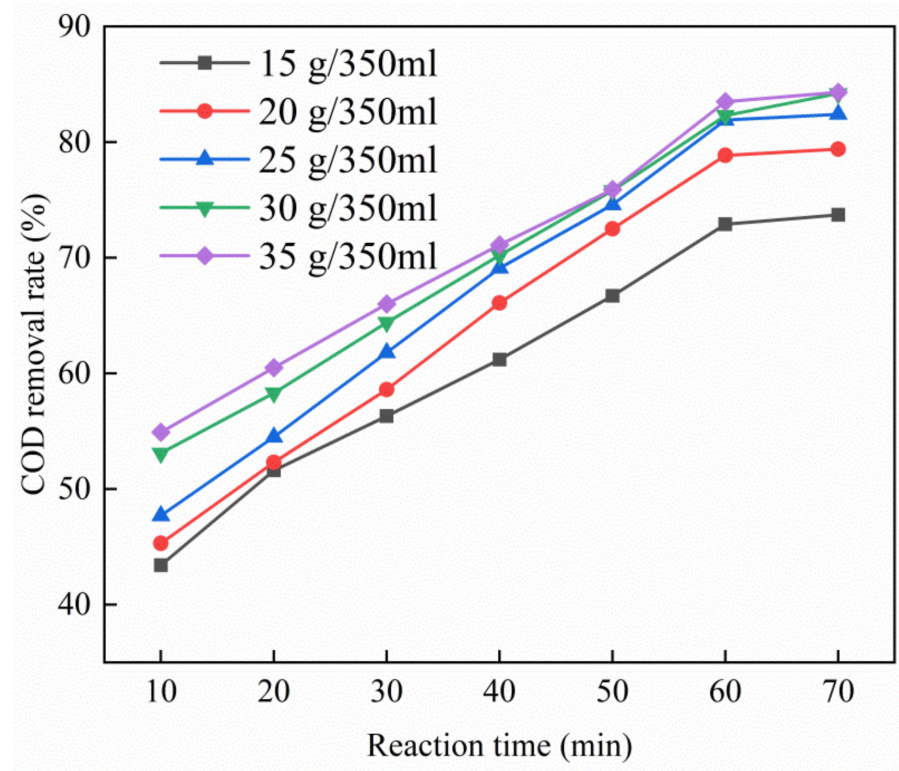

Figure 6. Effect of catalyst dosage on catalytic performance of $\mathrm{Cu}-\mathrm{Ce} @ \mathrm{Az}$ catalysts.

\subsection{Stability Analysis of $\mathrm{Cu}-\mathrm{Ce} @ A z$ Ozone Catalyst}

As shown in Figure 7, as the number of repeated uses of the $\mathrm{Cu}-\mathrm{Ce} @ \mathrm{Az}$ ozone catalyst increased, the removal rate of COD from the PTA wastewater continued to decrease. The new $\mathrm{Cu}-\mathrm{Ce} @ \mathrm{Az}$ ozone catalyst treated the PTA wastewater for $70 \mathrm{~min}$. The COD removal rate of the PTA wastewater was $84.2 \%$. The $\mathrm{Cu}-\mathrm{Ce} @ \mathrm{Az}$ ozone catalyst was reused five times. The COD removal rate of the PTA wastewater was $82.1 \%$ and the COD removal rate was $82.1 \%$. The rate dropped by only $2.1 \%$. The $\mathrm{Cu}-\mathrm{Ce} @ \mathrm{Az}$ ozone catalyst was reused 30 times, and the COD removal rate of the PTA wastewater was $68.2 \%$. In general, the $\mathrm{Cu}-\mathrm{Ce} @ \mathrm{Az}$ ozone catalyst was stable and could meet the requirements of practical application.

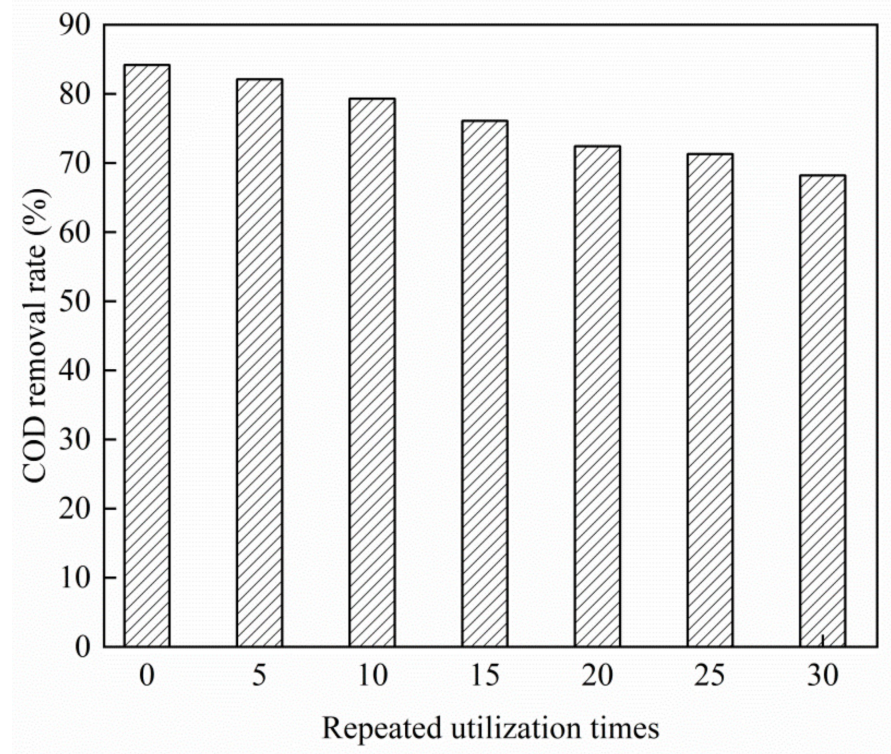

Figure 7. Effect of repeated utilization times on catalytic performance of $\mathrm{Cu}-\mathrm{Ce} @ \mathrm{Az}$ catalysts.

\subsection{Effect of Tert-Butanol Dosage on Catalytic Oxidation Performance}

As shown in Figure 8, the addition of tert-butanol can significantly reduce the removal rate of total organic carbon in an ozone catalytic system. However, the reduction of the COD removal rate of the PTA wastewater in a single ozone reaction system was not significant. By contrast, the reduction of the COD removal rate of the PTA wastewater in the 
ozone + $\mathrm{Cu}-\mathrm{Ce} @ A z$ ozone catalyst reaction system was more obvious. When the concentration of tert-butanol was the maximum, $160 \mathrm{mg} / \mathrm{L}$, in the ozone reaction system alone the COD removal rate of the PTA wastewater decreased by $3.9 \%$, while the COD removal rate of the PTA wastewater in the ozone + $\mathrm{Cu}-\mathrm{Ce} @ \mathrm{Az}$ ozone catalyst reaction system decreased by $50.7 \%$. This result means that hydroxyl radicals dominate the $\mathrm{Cu}-\mathrm{Ce} @ \mathrm{Az}$ ozone catalyst reaction system. When the concentration of tert-butanol is 20,40 , and $80 \mathrm{mg} / \mathrm{L}$, the removal rate of COD in the PTA wastewater decreased significantly, and excessive tert-butanol may have occupied a large number of active sites on the catalyst and inhibited free radicals [31]. Furthermore, the remaining tert-butanol did not have enough active sites to bind and could not be fully utilized, and the removal rate was slowed down. The inhibition of tributyltin compounds did not prevent the ozone from oxidizing organic pollutants in the tailwater [32]. Therefore, tert-butanol can only inhibit but not prevent the catalytic oxidation of ozone.
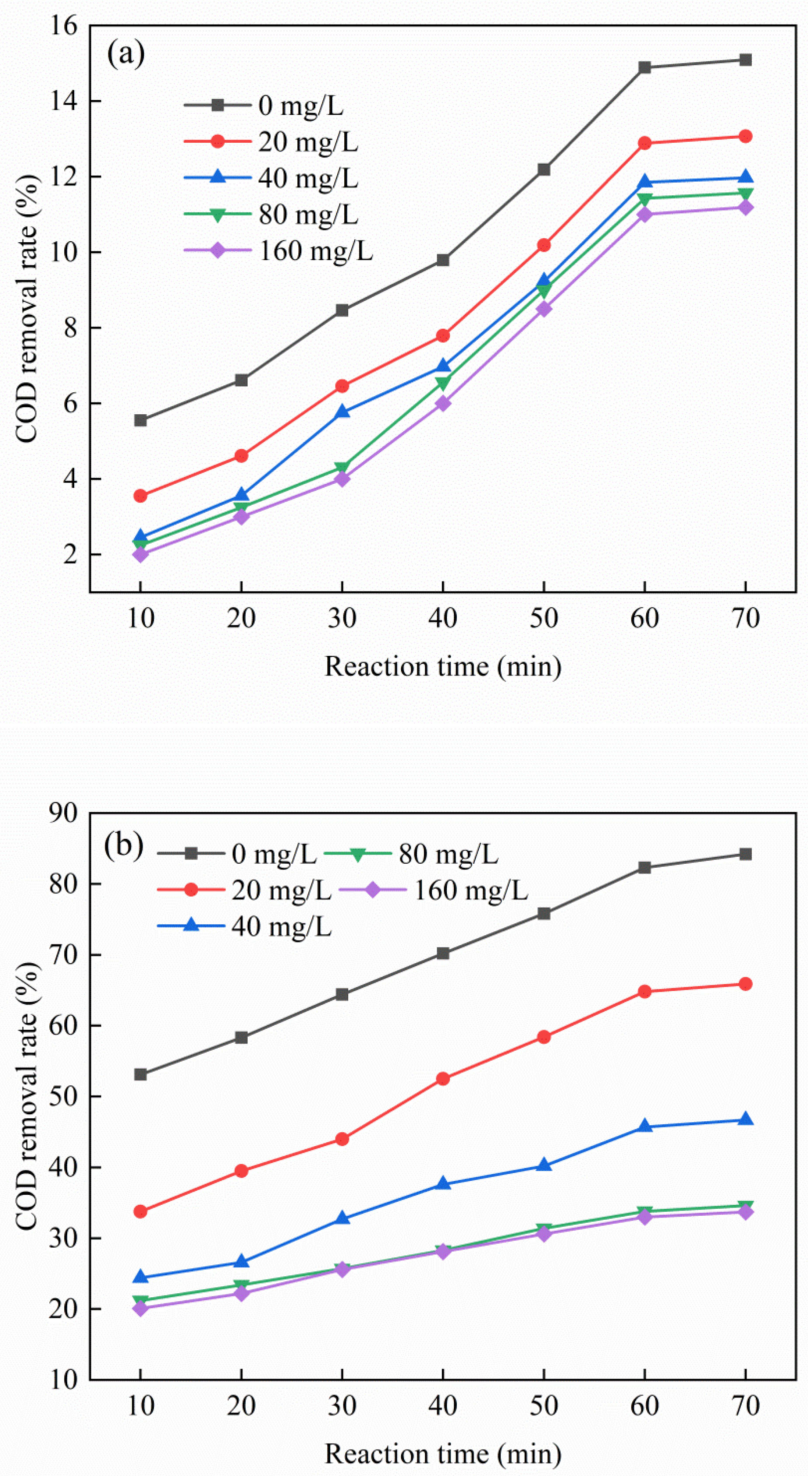

Figure 8. Effect of tert-butanol dosage on ozone catalytic oxidation system: (a) ozone alone and (b) ozone + $\mathrm{Cu}-\mathrm{Ce} @ \mathrm{Az}$ catalysts.

\subsection{D Fluorescence Spectrum Analysis}

As shown in Figure 9, the raw water of the PTA wastewater that had not been treated with the $\mathrm{Cu}-\mathrm{Ce} @ \mathrm{Az}$ ozone catalyst had a relatively high 3D fluorescence intensity, and the fluorescence intensity value could reach 93,500 between the emission wavelengths 
of 350-500 nm. After ozone-catalyzed oxidation, the fluorescence intensity of the water sample could be detected in the range of 300-600 nm. However, compared with the raw water, the fluorescence intensity value at that time was only 3810, and the 3D fluorescence intensity of the water sample was reduced 24.54 times. By comparing the changes in the 3D fluorescence spectrum intensity of the PTA wastewater before and after treatment, we can observe that the $\mathrm{Cu}-\mathrm{Ce} @ \mathrm{Az}$ ozone catalyst could effectively remove the organic matter in the PTA wastewater. The fluorescence intensity of the water sample detected between the emission wavelengths (EM) 300-500 nm and the excitation wavelengths (EX) 280-420 $\mathrm{nm}$ of the PTA wastewater indicates that it contains humic organic matter, fulvic acid organic matter, and soluble microorganism-produced organic matter [33]. After treatment, the fluorescence intensity of the PTA wastewater weakened at EM $=350-500 \mathrm{~nm}$ and $\mathrm{EX}=280-400 \mathrm{~nm}$, indicating that humic organic matter, fulvic acid organic matter, and organic matter produced by soluble microorganisms had been removed [34]. The fluorescence intensity of water samples could be detected at EM $=350-500 \mathrm{~nm}$ and $E X=270-400 \mathrm{~nm}$, which shows that the organic matter in the PTA wastewater was converted into new substances such as tryptophan organic matter.
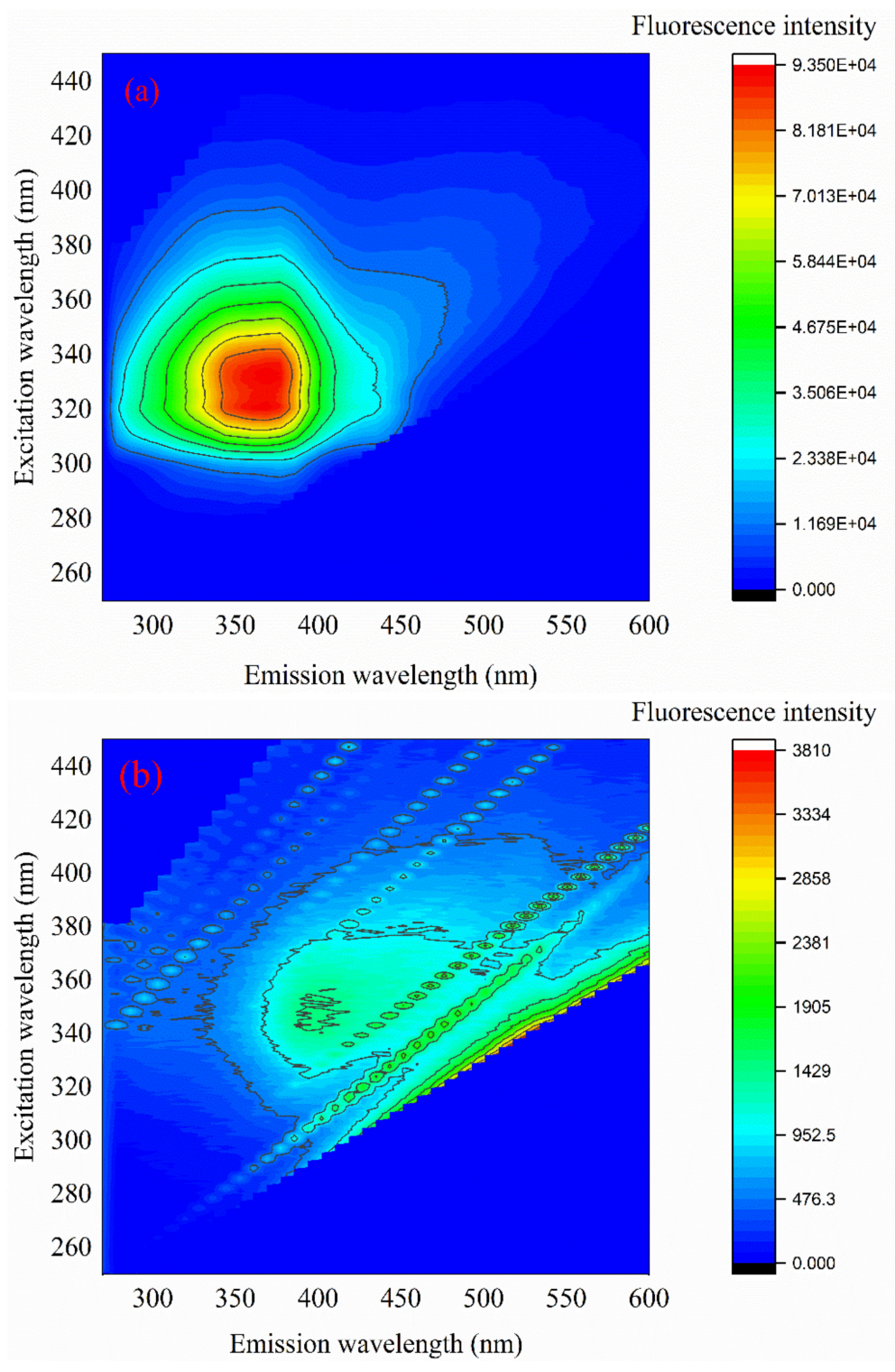

Figure 9. 3D fluorescence spectra of PTA wastewater under different conditions: (a) before treatment and $(\mathbf{b})$ after treatment. 


\subsection{Ultraviolet Absorption Peak of PTA Wastewater}

As shown in Figure 10, the ultraviolet absorption peak of the water sample at $\lambda=190-220 \mathrm{~nm}$ decreased significantly, which indicates that the unsaturated organic matter, some conjugated structures, and the benzene ring system in the PTA wastewater had been removed. Over time, a new UV absorption peak appeared at $\lambda=220-350 \mathrm{~nm}$, indicating that new substances were produced in the PTA wastewater. After $\lambda=350 \mathrm{~nm}$, no significant change occurred in the UV absorption peak of the water sample, indicating that most of the pollutants in the PTA wastewater had been degraded. Furthermore, the continued reaction effect was not good, which shows that the organic pollutants in the PTA wastewater had been removed.

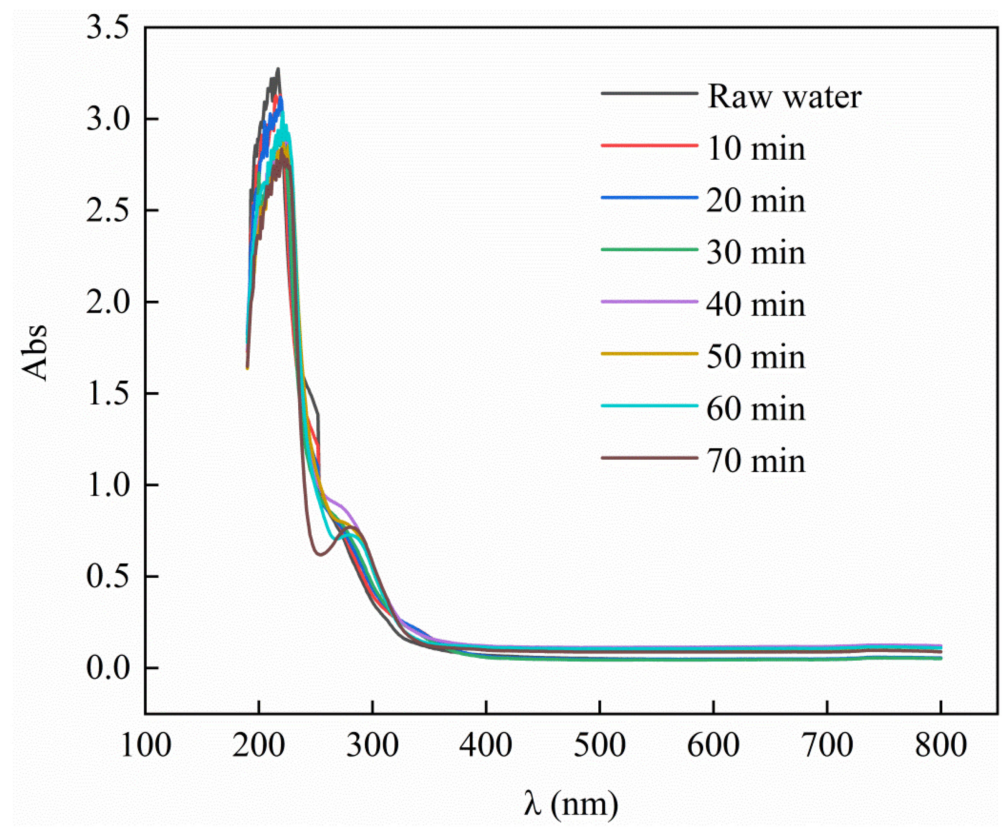

Figure 10. UV-Vis diagram of PTA wastewater at different ozone catalytic oxidation times.

\section{Conclusions}

In this study, a $\mathrm{Cu}-\mathrm{Ce} @ \mathrm{Az}$ ozone catalyst was prepared by loading the metallic elements $\mathrm{Cu}$ and $\mathrm{Ce}$ on an artificial zeolite through the impregnation method. A systematic experimental study was conducted. The characterization results showed that the metallic elements $\mathrm{Cu}$ and $\mathrm{Ce}$ were successfully loaded inside and on the surface of the carrier. After calcination, the metallic elements $\mathrm{Cu}$ and $\mathrm{Ce}$ existed in the state of oxides $\mathrm{CuO}$ and $\mathrm{CeO}_{2}$. The optimal reaction conditions for the $\mathrm{Cu}-\mathrm{Ce} @ \mathrm{Az}$ ozone catalyst to treat PTA wastewater were as follows: $70 \mathrm{~min}$ reaction time, $\mathrm{pH}=8.5,2 \mathrm{~g} / \mathrm{h}$ ozone dosage, and $30 \mathrm{~g} / 350 \mathrm{~mL}$ catalyst dosage. Under these conditions, the removal rate of COD from the PTA wastewater by the $\mathrm{Cu}-\mathrm{Ce} @ \mathrm{Az}$ ozone catalyst reached $84.2 \%$. The $\mathrm{Cu}-\mathrm{Ce} @ \mathrm{Az}$ ozone catalyst was reused 30 times and the COD removal rate of the PTA wastewater was $68.2 \%$, which was still a high removal rate. Water quality characterization showed that after catalytic oxidation reaction, organic matter in the PTA wastewater had been converted into tryptophan organic matter and aromatic organic matter. Furthermore, unsaturated organic matter, certain conjugated structures, and the benzene ring system in the wastewater were destroyed.

Supplementary Materials: The following are available online at https:/ /www.mdpi.com/article/10 $.3390 / w 13141906 /$ s1, Figure S1: Adsorption experiment of PTA biochemical tailwater by artificial zeolite, Figure S2: The effect of element impregnation ratio on the oxidation efficiency of PTA biochemical tailwater (roasting temperature $300^{\circ} \mathrm{C}$, roasting time $3 \mathrm{~h}, \mathrm{pH}=8.5$, reaction time $70 \mathrm{~min}$, catalyst dosage $75 \mathrm{~g} / \mathrm{L}$, ozone generation $1.5 \mathrm{~g} / \mathrm{h}$, aeration $0.05 \mathrm{~L} / \mathrm{min}$ ), Figure S3: The effect of roasting temperature on the oxidation efficiency of PTA biochemical tailwater (impregnation ratio of $\mathrm{Cu}: \mathrm{Ce}=1: 3$, calcination time $3.0 \mathrm{~h}, \mathrm{pH}=8.5$, reaction time $70 \mathrm{~min}$, catalyst dosage $75 \mathrm{~g} / \mathrm{L}$, ozone 
generation $1.5 \mathrm{~g} / \mathrm{h}$, aeration $0.05 \mathrm{~L} / \mathrm{min}$ ), Figure $\mathrm{S} 4$ : The effect of roasting time on the oxidation efficiency of PTA biochemical tailwater (impregnation ratio of $\mathrm{Cu}: \mathrm{Ce}=1: 3$, calcination temperature $400{ }^{\circ} \mathrm{C}, \mathrm{pH}=8.5$, reaction time $70 \mathrm{~min}$, catalyst dosage $75 \mathrm{~g} / \mathrm{L}$, ozone generation $1.5 \mathrm{~g} / \mathrm{h}$, aeration $0.05 \mathrm{~L} / \mathrm{min})$, Figure S5: XRD characterization of $\mathrm{Cu}-\mathrm{Ce} @ \mathrm{Az}$ catalysts, Figure S6: Adsorption and desorption isotherms: (a) synthetic zeolite, (b) Cu-Ce@Az catalyst, (c) Cu-Ce@Az after utilization 30 times, Figure S7: XPS characterization: (a) synthetic zeolite, (b) Cu-Ce@Az catalyst, (c) Cu-Ce@Az after utilization 30 times, Table S1: BET characterization analysis of Cu-Ce@Az catalyst, Table S2: XRF characterization of $\mathrm{Cu}-\mathrm{Ce} @ \mathrm{Az}$ catalyst, Table S3: EDS characterization of $\mathrm{Cu}-\mathrm{Ce} @ \mathrm{Az}$ catalyst.

Author Contributions: Conceptualization, X.L., S.X., S.L. and J.Z.; methodology, S.L., J.Z., W.S., Y.X. and Y.S.; software, Y.S.; validation, J.Z., W.S. and Y.S.; formal analysis, X.L., S.L., J.Z., W.S. and Y.S.; investigation, S.L., J.Z., W.S. and Y.S.; data curation, S.L., W.S. and Y.S.; writing-original draft preparation, S.L., W.S. and Y.S.; writing-review and editing, W.S. and Y.S.; supervision, W.S. and Y.S.; project administration, W.S. and Y.S.; funding acquisition, Y.S. All authors have read and agreed to the published version of the manuscript.

Funding: This research was supported by the National Natural Science Foundation of China (No. 51508268), Natural Science Foundation of Jiangsu Province in China (No. BK20201362), and 2018 Six Talent Peaks Project of Jiangsu Province (JNHB-038).

Institutional Review Board Statement: Not applicable.

Informed Consent Statement: Not applicable.

Data Availability Statement: The data presented in this study are available on request from the corresponding author.

Conflicts of Interest: The authors declare no conflict of interest.

\section{References}

1. Sun, W.; Zhou, S.; Sun, Y.; Xu, Y.; Zheng, H. W-Ag-Ti@ $\gamma-\mathrm{Al} 2 \mathrm{O} 3$ particle electrodes for enhanced electrocatalytic pretreatment of coal chemical wastewater. J. Environ. Chem. Eng. 2021, 9, 104681. [CrossRef]

2. Sun, W.; Sun, Y.; Zhu, H.; Zheng, H. Catalytic activity and evaluation of Fe-Mn@Bt for ozonizing coal chemical biochemical tail water. Sep. Purif. Technol. 2020, 239, 116524. [CrossRef]

3. Krishan, K.G.; Basheshwar, P. Treatment of toxic pollutants of purified terephthalic acid waste water: A review. Environ. Technol. Innov. 2017, 8, 191-217.

4. Wang, D.; Ma, W.; Han, H.; Li, K.; Xu, H.; Fang, F.; Hou, B.; Jia, S. Enhanced anaerobic degradation of Fischer-Tropsch wastewater by integrated UASB system with Fe-C micro-electrolysis assisted. Chemosphere 2016, 164, 14-24. [CrossRef] [PubMed]

5. Yu, J.; Qiu, W.; Xu, H.; Lu, X.; Ma, J.; Lu, D. Highly-efficient and stable MgCo2O4 spinel for bisphenol a removal by activating peroxymonosulfate via radical and non-radical pathways. Chem. Eng. J. 2021, 421, 129498. [CrossRef]

6. Sheikhi, S.; Dehghanzadeh, R.; Maryamabadi, A.; Aslani, H. Chlorpyrifos removal from aqueous solution through sequential use of coagulation and advanced oxidation processes: By-products, degradation pathways, and toxicity assessment. Environ. Technol. Innov. 2021, 23, 101564. [CrossRef]

7. Jiang, Y.; Zhao, H.; Liang, J.; Yue, L.; Li, T.; Luo, Y.; Liu, Q.; Lu, S.; Asiri, A.M.; Gong, Z.; et al. Anodic oxidation for the degradation of organic pollutants: Anode materials, operating conditions and mechanisms. A mini review. Electrochem. Commun. 2021, 123, 106912. [CrossRef]

8. Zhang, J.; Zhou, Y.; Yao, B.; Yang, J.; Zhi, D. Current progress in electrochemical anodic-oxidation of pharmaceuticals: Mechanisms, influencing factors, and new technique. J. Hazard. Mater. 2021, 418, 126313. [CrossRef]

9. Saad, M.E.K.; Rabaaoui, N.; Elaloui, E.; Moussaoui, Y. Mineralization of p-methylphenol in aqueous medium by anodic oxidation with a boron-doped diamond electrode. Sep. Purif. Technol. 2016, 171, 157-163. [CrossRef]

10. Ridruejo, C.; Salazar, C.; Cabot, P.L.; Centellas, F.; Brillas, E.; Sirés, I. Electrochemical oxidation of anesthetic tetracaine in aqueous medium. Influence of the anode and matrix composition. Chem. Eng. J. 2017, 326, 811-819. [CrossRef]

11. Wu, M.; Kwok, Y.H.; Zhang, Y.; Szeto, W.; Huang, H.; Leung, D.Y. Synergetic effect of vacuum ultraviolet photolysis and ozone catalytic oxidation for toluene degradation over MnO2-rGO composite catalyst. Chem. Eng. Sci. 2021, 231, 116288. [CrossRef]

12. Gopi, T.; Swetha, G.; Shekar, S.C.; Krishna, R.; Ramakrishna, C.; Saini, B.; Rao, P. Ozone catalytic oxidation of toluene over 13X zeolite supported metal oxides and the effect of moisture on the catalytic process. Arab. J. Chem. 2019, 12, 4502-4513. [CrossRef]

13. Pang, L.; Fan, C.; Shao, L.; Song, K.; Yi, J.; Cai, X.; Wang, J.; Kang, M.; Li, T. The Ce doping Cu/ZSM-5 as a new superior catalyst to remove NO from diesel engine exhaust. Chem. Eng. J. 2014, 253, 394-401. [CrossRef]

14. Shao, Q.; Dong, H.; Zhang, J.; Xu, B.; Wu, Y.; Long, C. Manganese supported on controlled dealumination Y-zeolite for ozone catalytic oxidation of low concentration toluene at low temperature. Chemosphere 2021, 271, 129604. [CrossRef] 
15. Sun, W.; Zhou, S.; Sun, Y.; Tang, J.; Zheng, H. Ozone catalytic oxidation capacity of Ti-Co@Al 2 O 3 for the treatment of biochemical tail water from the coal chemical industry. Water Environ. Res. 2020, 92, 1283-1292. [CrossRef]

16. Kim, J.; Kwon, E.E.; Lee, J.E.; Jang, S.-H.; Jeon, J.-K.; Song, J.; Park, Y.-K. Effect of zeolite acidity and structure on ozone oxidation of toluene using Ru-Mn loaded zeolites at ambient temperature. J. Hazard. Mater. 2021, 403, 123934. [CrossRef]

17. Sun, W.; Sun, Y.; Shah, K.; Zheng, H.; Ma, B. Electrochemical degradation of oxytetracycline by Ti-Sn-Sb/ $\gamma-\mathrm{Al} 2 \mathrm{O} 3$ threedimensional electrodes. J. Environ. Manag. 2019, 241, 22-31. [CrossRef] [PubMed]

18. He, S.; Luan, P.; Mo, L.; Xu, J.; Li, J.; Zhu, L.; Zeng, J. Mineralization of Recalcitrant Organic Pollutants in Pulp and Paper Mill Wastewaters through Ozonation Catalyzed by Cu-Ce Supported on Al2O3. Bioresources 2018, 13, 3686-3703. [CrossRef]

19. Sun, Y.; Chen, A.; Zhu, S.; Sun, W.; Shah, K.; Zheng, H. Degradation of chloramphenicol using Ti-Sb/attapulgite ceramsite particle electrodes. Water Environ. Res. 2019, 91, 756-769. [CrossRef]

20. Dou, B.; Liu, D.; Zhang, Q.; Zhao, R.; Hao, Q.; Bin, F.; Cao, J. Enhanced removal of toluene by dielectric barrier discharge coupling with Cu-Ce-Zr supported ZSM-5/TiO2/Al2O3. Catal. Commun. 2017, 92, 15-18. [CrossRef]

21. Águila, G.; Gracia, F.; Araya, P. $\mathrm{CuO}$ and $\mathrm{CeO} 2$ catalysts supported on $\mathrm{Al} 2 \mathrm{O} 3, \mathrm{ZrO} 2$, and $\mathrm{SiO} 2$ in the oxidation of $\mathrm{CO}$ at low temperature. Appl. Catal. A Gen. 2008, 343, 16-24. [CrossRef]

22. Park, J.W.; Jeong, J.H.; Yoon, W.L.; Rhee, Y.W. Selective oxidation of carbon monoxide in hydrogen-rich stream over Cu-Ce $/ \gamma$-Al2O3 catalysts promoted with cobalt in a fuel processor for proton exchange membrane fuel cells. J. Power Sources 2004, 132, 18-28. [CrossRef]

23. Francisco, M.S.P.; Mastelaro, V.; Nascente, P.A.P.; Florentino, A.O. Activity and Characterization by XPS, HR-TEM, Raman Spectroscopy, and BET Surface Area of CuO/CeO2-TiO2 Catalysts. J. Phys. Chem. B 2001, 105, 10515-10522. [CrossRef]

24. Chen, L.; Zhu, Y.; Zheng, H.; Zhang, C.; Zhang, B.; Li, Y. Catalytic degradation of oxygenates in Fischer-Tropsch aqueous phase effluents to fuel gas via hydrodeoxygenation over Ru/AC catalyst. J. Chem. Technol. Biotechnol. 2011, 87, 112-122. [CrossRef]

25. Bae, S.; Jung, J.; Lee, W. The effect of $\mathrm{pH}$ and zwitterionic buffers on catalytic nitrate reduction by TiO2-supported bimetallic catalyst. Chem. Eng. J. 2013, 232, 327-337. [CrossRef]

26. Qi, F.; Chen, Z.; Xu, B.; Shen, J.; Ma, J.; Joll, C.; Heitz, A. Influence of surface texture and acid-base properties on ozone decomposition catalyzed by aluminum (hydroxyl) oxides. Appl. Catal. B Environ. 2008, 84, 684-690. [CrossRef]

27. Lan, Q.; Cao, M.; Ye, Z.; Zhu, J.; Chen, M.; Chen, X.; Liu, C. Effect of oxalate and pH on photodegradation of pentachlorophenol in heterogeneous irradiated maghemite System. J. Photochem. Photobiol. A Chem. 2016, 328, 198-206. [CrossRef]

28. Zhang, L.-C.; Jia, Z.; Lyu, F.; Liang, S.-X.; Lu, J. A review of catalytic performance of metallic glasses in wastewater treatment: Recent progress and prospects. Prog. Mater. Sci. 2019, 105, 100576. [CrossRef]

29. Xia, F.; Xu, X.; Li, X.; Zhang, L.; Qiu, H.; Wang, W.; Liu, Y.; Gao, J. Preparation of Bismuth Nanoparticles in Aqueous Solution and Its Catalytic Performance for the Reduction of 4-Nitrophenol. Ind. Eng. Chem. Res. 2014, 53, 10576-10582. [CrossRef]

30. Chen, H.-S.; Zhang, Q.-M.; Yang, Z.-J.; Liu, Y.-S. Research on Treatment of Oily Sludge from the Tank Bottom by Ball Milling Combined with Ozone-Catalyzed Oxidation. ACS Omega 2020, 5, 12259-12269. [CrossRef]

31. Sun, Y.; Zhu, S.; Sun, W.; Zheng, H. Degradation of high-chemical oxygen demand concentration pesticide wastewater by 3D electrocatalytic oxidation. J. Environ. Chem. Eng. 2019, 7, 103276. [CrossRef]

32. Sun, Y.; Chen, A.; Sun, W.; Zhou, J.; Shah, K.J.; Zheng, H.; Shen, H. Degradation of chloramphenicol by Ti-Ag/gamma-Al ${ }_{2} \mathrm{O}_{3}$ particle electrode using three-dimensional reactor. Desalin. Water. Treat. 2019, 163, 96-108. [CrossRef]

33. Zhu, G.; Wang, C.; Dong, X. Fluorescence excitation-emission matrix spectroscopy analysis of landfill leachate DOM in coagulation-flocculation process. Environ. Technol. 2016, 38, 1489-1497. [CrossRef] [PubMed]

34. Tang, X.; Huang, T.; Zhang, S.; Zheng, J.; Zheng, H. Synthesis of an amphoteric chitosan-based flocculant and its flocculation performance in the treatment of dissolved organic matter from drinking water. Desalination Water Treat. 2020, 174, 171-177. [CrossRef] 